Volume 101, Number 3

Special Issue

Crystallographic Databases

\title{
Journal of Research of the
}

National

Institute of

Standards and

Technology 

to modernize manufacturing processes, to ensure product reliability . . . and to facilitate rapid commercialization . . . of products based on new scientific discoveries."

NIST, originally founded as the National Bureau of Standards in 1901, works to strengthen U.S. industry's competitiveness; advance science and engineering; and improve public health, safety, and the environment. One of the agency's basic functions is to develop, maintain, and retain custody of the national standards of measurement, and provide the means and methods for comparing standards used in science, engineering, manufacturing, commerce, industry, and education with the standards adopted or recognized by the Federal Government.

As an agency of the U.S. Commerce Department's Technology Administration, NIST conducts basic and applied research in the physical sciences and engineering, and develops measurement techniques, test methods, standards, and related services. The Institute does generic and precompetitive work on new and advanced technologies. NIST's research facilities are located at Gaithersburg, MD 20899, and at Boulder, CO 80303. For more information contact the Public Inquiries Desk, 301-975-3058. 


\section{Journal of Research of the National Institute of Standards and Technology}

\section{Board of Editors}

Barry N. Taylor

Chief Editor

Nancy M. Trahey, Technology Services

Richard J. Van Brunt, Electronics and Electrical Engineering Laboratory

Theodore V. Vorburger, Manufacturing Engineering Laboratory

John R. Moody, Chemical Science and Technology Laboratory

Ronald Collé, Physics Laboratory

Kenneth L. Jewett, Materials Science and Engineering Laboratory

Piotr A. Domanski, Building and Fire Research Laboratory

Alan H. Goldfine, Computer Systems Laboratory

Daniel W. Lozier, Computing and Applied Mathematics Laboratory

Matt Young, Boulder Laboratories

Chris E. Kuyatt, Washington Editorial Review Board

Donald R. Harris

Managing Editor

Julian M. Ives

Technical Production Editor

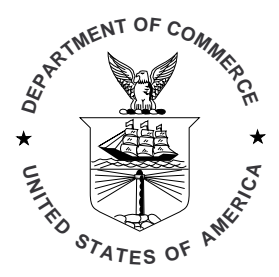


The Journal of Research of the National Institute of Standards and Technology features advances in measurement methodology and analyses consistent with the NIST responsibility as the nation's measurement science laboratory. It includes reports on instrumentation for making accurate and precise measurements in fields of physical science and engineering, as well as the mathematical models of phenomena which enable the predictive determination of information in regions where measurements may be absent. Papers on critical data, calibration techniques, quality assurance programs, and well-characterized reference materials reflect NIST programs in these areas. Special issues of the Journal are devoted to invited papers in a particular field of measurement science. Occasional survey articles and conference reports appear on topics related to the Institute's technical and scientific programs. 


\section{NIST Workshop on Crystallographic Databases}

\section{Preface}

Special issues of the Journal of Research of the National Institute of Standards and Technology are devoted to papers in a particular field of measurement science. The papers herein have been written by leading experts in the field and focus on the present status and future potential of crystallographic databases. These papers, which were presented at the NIST Workshop on Crystallographic Databases, held in Gaithersburg, MD, August 1995, clearly show that crystallographic databases will have a major impact on the advancement of science and technology. Daniel B. Butrymowicz (deceased) of the materials Science and Engineering Laboratory and the NIST Publications Production Program, especially Julian Ives, deserve recognition for their dedicated efforts in producing this volume.

Vicky Lynn Karen Alan Mighell

Special Issue Editors 


\section{Foreword}

One of the most amazing facts about nature is how the fundamental particles combine into three basic building blocks - the proton, neutron and electron - under the conditions found on earth. Equally amazing is that these three particles can be aggregated into a hundred or so formations, called atoms, that form the basis of life and nature as we know it. As we aggregate atoms into molecules and compounds, the number of possible combinations becomes infinite, yet the regularity persists. This regularity of construction is marvelous, yet taken for granted.

Function follows form, and the function and properties of compounds are determined by their structure. Crystallography is the study of the structure of regular solid-state substances, and its importance is hard to overestimate. Crystallography was one of the first scientific disciplines to computerize, thereby allowing the determination of simple structures to become straightforward and of complicated structures to be possible. A natural consequence of using the computer to generate data was to use it to archive data already generated. Crystallography and neutron physics were in fact among the first areas to create numerical scientific databases. Over the last 40 years, the importance of crystallographic database work has grown enormously. Virtually all structure determinations have been archived in databases which allow easy access and complete coverage. Thousands of scientists all over the world successfully use these databases on a daily basis for a wide variety of applications.

Today, the computer revolution continues: new processors allow computations of a scale impossible just 15 years ago; database technology makes data storage and retrieval easy; and the internet makes data access trivial. How do these developments affect existing crystallographic data activities, which have evolved into a coordinated, comprehensive set of separate activities? What are the new demands that the scientific community is placing on the crystallographic data activities now that materials design from first principles is becoming a reality? Finally, what new efforts are needed to enhance the data activities, perhaps having them become more integrated? Questions such as these made it timely to organize this workshop on the crystallographic databases and to have a frank and open discussion amongst the representatives of the data activities with input from users. The reader will find in these pages not only a review of all existing crystallographic data activities, but also some answers to the questions just raised.

The NIST Standard Reference Data Program has long supported many crystallographic data efforts and is very interested in promoting discussions on issues related to the collection, evaluation, and dissemination of crystallographic data. Dr. Mary Good, Under Secretary of Technology in the U.S. Department of Commerce, joins me in thanking Vicky Lynn Karen and Alan Mighell of the NIST Crystal and Electron Diffraction Data Center for organizing the workshop and pulling together these proceedings. Opportunities for growth in terms of the nature and scope of new data activities and greater cooperation have been identified. We all look forward to further progress in meeting the need to preserve and access data on one of nature's most marvelous creations: the regularity of the structure of matter.

John Rumble, Chief

NIST Standard Reference Data Program 
Contents

Special Issue: NIST Workshop on Crystallographic Databases

Vicky Lynn Karen and Alan Mighell, Editors

Preface

Foreword

\section{Articles}

CRYSTMET-The NRCC Metals Crystallographic Data File

Inorganic Crystal Structure Database (ICSD) and Standardized Data and Crystal Chemical Characterization of Inorganic Structure Types (TYPIX)—Two Tools for Inorganic Chemists and Crystallographers

Evaluation of Crystallographic Data with the Program DIAMOND

The Cambridge Structural Database (CSD): Current Activities and Future Plans

The Protein Data Bank: Current Status and Future Challenges

The Nucleic Acid Database: Present and Future

The Powder Diffraction File: Past, Present, and Future

NIST Crystallographic Databases for Research and Analysis

Conventional and Eccentric Uses of Crystallographic

Databases in Practical Materials Identification Problems

Using NIST Crystal Data Within Siemens Software for Four-Circle and SMART CCD Diffractometers
Gordon H. Wood, John R.

Rodgers, S. Roger Gough, and

Pierre Villars

Ekkehard Fluck

Günter Bergerhoff, Michael Berndt, 221 and Klaus Brandenburg

David G. Watson

Enrique E. Abola, Nancy O. Manning, 231 Jaime Prilusky, David R. Stampf, and Joel L. Sussman

Helen M. Berman, Anke Gelbin, Lester Clowney, Shu-Hsin Hsieh, Christine Zardecki, and John

Westbrook

Deane K. Smith and

Ron Jenkins

Alan D. Mighell and

Vicky Lynn Karen

James A. Kaduk

Susan K. Byram, Charles F. Campana, James Fait, and Robert A. Sparks

Phase Identification in a Scanning Electron Microscope R. P. Goehner and J. R. Michael 301 
The Biological Macromolecule Crystallization Database

Gary L. Gilliland, Michael Tung, and NASA Protein Crystal Growth Archive and Jane Ladner

Investigations of the Systematics of Crystal Packing Using the

Cambridge Structural Database

Troublesome Crystal Structures: Prevention, Detection,

Richard L. Harlow and Resolution

CIF (Crystallographic Information File): A Standard for Crystallographic Data Interchange

The Role of Journals in Maintaining Data Integrity:

Brian McMahon

Checking of Crystal Structure Data in

Acta Crystallographica

Electronic Publishing and the Journals of the American Chemical Society

Jeffrey D. Spring and

How the Cambridge Crystallographic Data Centre

Lorrin R. Garson

Obtains its Information

David G. Watson

Data Import and Validation in the Inorganic Crystal

H. Behrens

Structure Database

World Wide Web for Crystallography

H. D. Flack

\section{Conference Reports}

Workshop on Characterizing Diamond Films IV

Quest for Excellence VIII
Albert Feldmann, Ajay P. Malshe, and John E. Graebner

Cap Frank

\section{News Briefs}

\section{GENERAL DEVELOPMENTS}

NIST Calibration Heart-ening for New Treatment

MAMTC Helps Small Businesses Improve, Cut Costs

New Josephson Voltage Standard Proposed

Compact Model of Voltage Standard Rolled Out 
Turbine Blades "Cast" in Starring Role by X Rays

"Airbag", Technology May Soon Snuff Fires

Engine Fuels Law to be Changed to Protect Consumers

Energy-Related Inventions Program Recommendations

NIST Testing Strategies Applied to Calibration Service Reduces Cost to Customer

NIST Establishes Traceability Link With Electrical Metrology Laboratories in Ecuador

Results of NIST-Led Intercomparison Offer Clues for Improved High-Frequency

Measurements of Dielectric and Magnetic Parameters

NIST Develops Three-Axis Correction Method Needed for Measurements of Satellite

Steered-Beam Antennas

High Speed Milling

New Calibration Service Developed for High Pressure Gas

Patent Issued on Metal Silicide Thermocouple

Entangled Polarization States Provide High Resolution Vernier for Polarization

Mode Dispersion Measurement

Analysis of the Complex Rotational Spectrum of $\mathrm{N}_{2} \mathrm{O}_{5}$ Obtained for the First Time

Magnetic Resonance Imaging With Laser-polarized ${ }^{3} \mathrm{He}$ Gas

Reference Radiographs for Aluminum Welds

Relationship Between Mechanical and Magnetic Properties of Sheet Steel

Neutron Crystallography of Colossal Magnetoresistors

NIST Collaborates with Insurance Company to Investigate New Residential Fire

Suppression Technologies

NIST STEP Validation Procedures Issued

NIST Publishes Version 3.0 of the Application Portability Profile

New Publication Presents Open System Environment Architectural Framework

World's Most Accurate Electron Counter Debuts

Seminar on Standards Information

NTEP Certificate of Conformance Issued for an Automatic Weighing System

Energy-Related Inventions Program Recommendations

NIST Demonstrates Breakthrough X-Ray Microcalorimeter

NIST Researcher Invents Method for Fabricating Thin-Film Narrow-Line Stencils

Report Presents Detailed Semiconductor Optical Characterization Survey Results

Footwear Industry Establishes Standards Committee as a Result of NIST's Efforts

Acoustic Field Transducers

Photomask Linewidth Standards

NIST Research Aids FBI and Forensic Laboratories

Detection and Characterization of Individual Nucleic Acid Polymers Using a Nanoscale Pore

Database on the Thermodynamics of Enzyme-catalyzed Reactions

Cavity Ring-Down Spectroscopy of Low Concentration Gases

Chemical Database Available on World Wide Web

Next-Generation Neutron Focusing Lens Characterized

Web Offering Used as Curricular Resource

Reflection in Magnetic Multilayers

New Spectroscopic Reference Data Compilation 
Field Retardation Observed in Molecules

IR Calibration of Hubble Space TelescopeInstrument

Calibration Source Will Provide On-Board Reliability of Collected Ocean Data

Fourier-Transform Analytical Microwave Spectroscopy: A New Tool for Analytical Chemists

Workshop on Quality Documentation for Medical X-Ray Calibration Laboratories

Slit Jet Discharges: A Novel, Intense Source of Supersonically Cooled Radicals and Molecular Ions

Optical Detection of Defects in Wide-Bandgap Semiconductor Films

Industrial Collaboration Shows Potential of New Measurement Method

New Report Addresses Industrial Research Needs in Electronic Materials

A Silver-Based Substitute for Mercury Containing Dental Amalgams

Record Setting Values in Giant Magnetoresistance Spin Valves

Wetting of Polymer Brushes

Limited Water Supply Fire Suppression Technologies

NIST Estimates Nationwide Energy Impact of Air Leakage in U.S. Office Buildings

NIST Starts Study of Residential Carbon Monoxide Detectors

NIST Conducts Computer Analysis to Analyze Moisture Control Practices in Manufactured Housing

NIST Publishes Guidelines for Evaluating Electronic Data Interchange (EDI) Products

New Publication Focuses on C++ in Safety Critical Systems

Data Communications Strategy Document Focuses on Networking Technologies and Interoperability Issues

STANDARD REFERENCE MATERIALS

A New SRM Developed in PED

New SRM Is Heavy Duty for Measuring Fats

STANDARD REFERENCE DATA

Transient Molecules Database Expanded 


\section{Introduction}

Scientific databases are becoming critical to research in the industrial and academic communities. The NIST Workshop on Crystallographic Databases was one in a series of NIST sponsored workshops each focusing on a particular type of data including, among others, crystallographic, thermodynamic, phase diagram, and mass spectral data. By bringing together top scientists involved in producing crystallographic data with users of the resulting databases, this Workshop served as a forum to examine how well the needs of the scientific community are being met and what data activities the community feels are important in the future. During the Workshop, three sessions of scientific presentations were held-(1) Formal Data Activities; (2) Scientific Uses of the Databases; and (3) Data Transfer: ensuring state of the art technology. In the first session, a representative from each of the data centers covered present activities and projected future activities of their data center. In the second session, the focus was on using crystallographic databases in analysis, in the prediction of materials properties and in the design of new chemicals, pharmaceuticals, and materials. In the third session, speakers addressed issues related to data transfer such as data exchange standards, the role of journals in the evaluation of published data, data exchange between the journals and crystallographic data centers, and computerized modes of data dissemination.

Following the presentations, a discussion session focused on Barriers to the Use of Crystallographic Data and on Partnerships for the Future. After the Workshop, the speakers submitted manuscripts which are published in this issue of the NIST Journal of Research. Following these papers are highlights of the discussion session.

As anticipated, the Workshop was attended by a diverse group who use crystallographic data in their research or are involved with this data in some other capacity, such as managers of scientific projects, journal editors, on-line system designers, instrument manufacturers, and librarians, among others. The Workshop revealed that the users of crystallographic data are being well served. The Data Centers have built evaluated databases covering all classes of compounds and they have developed theories and scientific programs for standardizing, evaluating and searching the data. Nevertheless, the topics addressed herein clearly demonstrate that the data field is in a period of dynamic transition that is being driven by many factors including a greatly increased user demand for information. Many attendees commented that the Workshop was both instructive and useful, and that it should be repeated in a few years.

The Workshop was held on August 29-30, 1995 on the campus of the National Institute of Standards and Technology (NIST) in Gaithersburg, Maryland, with the Standard Reference Data Program (SRDP) acting as host. The Workshop had no external funding, and NIST's support was fundamental to its success. We are particularly grateful to Dr. John R. Rumble, Jr., Chief of SRDP, whose support was critical for making this Workshop happen. Likewise, we appreciate the suggestions and assistance of Jean Gallagher, Sabina Crisen, and other SRDP staff members.

Many scientists contributed to the Workshop and this publication. We sincerely thank the following - David G. Watson (Cambridge Crystallographic Data Centre), Carolyn P. Brock (University of Kentucky), and Brian McMahon (International Union of Crystallography) for organizing excellent and timely sessions and for their assistance in editing the manuscripts that appear in this issue of the NIST Journal of Research; and Judith Flippen-Anderson (Naval Research Laboratory) and the attendees for a thoughtful and productive discussion session.

Vicky Lynn Karen Alan Mighell Special Issue Editors 